\title{
Timeless Data
}

Ho Manh Toan

Phenikaa University

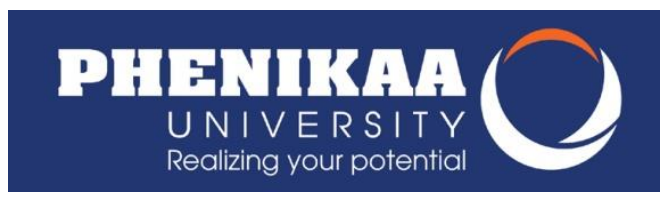

Hanoi, Vietnam

January 21, 2021

Despite modern technology, we still find ourselves immersed in the world of nostalgia. Vinyl records, black-and-white films, antiques, or classic books are all an embodiment of timelessness.

Despite its quest of finding truths, social sciences often have to face a dilemma: the limitation of the data. The reproducibility crisis is a notable example $[1,2,3]$. Indeed, parts of the problem lie in the statistics, research design, or fraudulence [2]. For studies that were done when the computational power or the Internet were luxury or even nonexistent, I feel like they never thought their data would be obsolete so soon. Moreover, Ben de Haas shared an interesting story of his retracted paper [4]. The data that was used for the paper suffered from undetected- biases. As Ben de Haas suggested, only simulations and stress tests can reveal the biases. The situation means the findings will never be corrected unless the authors or someone else realize that something is off.

Data are crucial to research. However, little discussion is surrounding the age of the data. Can data be timeless?

As data are collected in a specific time and place, a sense of topical and urgency is attached to the dataset. Therefore, subsequent papers are often published within five years since the dataset was available. The cyclical nature of some datasets also contributes to this mindset. National datasets are often conducted every 2 to 5 years. Thus, the researchers also tend to use the data in the same manner. We often talk about a classic paper, but we do not have the same expression regarding a dataset. Possibly, with the efforts from data journals like Scientific Data (Nature Publishing Group) or Data in Brief (Elsevier), and data repositories such as Harvard Dataverse or 
Open Science Framework (OSF), things will change. However, the current state indicates it would be a long time.

My feeling for the timelessness of data started with a simple observation. An article from 2009 used Vietnamese history in an unexpected fashion: a summary of wartime and wartime ratio to the whole duration of an era [5]. When I read the paper, I was working with the SSHPA database, whose structures and data are more complicated [6]. Nonetheless, the SSHPA database can be lost in time, but the historical data in the 2009 article will always be there. The author of the 2009 article continued with his experiments in other works [7-9]. Eventually, when I joined his lab in 2017, he taught me how to liberate a study from the limitation of newness and topicality of data.

"Color is too realistic. It is too distracting. It projects superfluous emotional cues. It reduces actors to inhabitants of the mere world. Black-and-white (or, more accurately, silver-and-white) creates a mysterious dream state, a simpler world of form and gesture." - Roger Ebert [10].

Color can look aged, but black-and-white is eternally enduring. Old things can get older, and history will always be history. Elbert or my mentor's realization was simple: the older the materials, the further they are from the newness.

However, there is no guarantee. History is stored in text, drawings, or architecture. They are not conveniently in an Excel file for statistical analysis. So, his intuition, and years of experiences, led him and the team on a journey of transfer fairy tales into a dataset $[11,12]$. Later, we continued experimenting with pictures of old houses in Hanoi [13], and old bibliometric data [14]

The fairy tales helped unearth a model called "cultural additivity," which suggested the arbitrariness in accepting new cultural values [11]. Thus, cultural additivity is a foundation for the acceptance (to a certain extent) of lies and violence in Vietnamese religions [12], as well as the mixture of French and Chinese culture on the façade of old houses in Hanoi. The stories are still being told to every Vietnamese child. The old houses, however, are being demolished and replaced. The bibliometric data of Vietnam mathematics touched upon a foundational history, in which the founders are now stories and legends [14].

During this time, a project called Seshat also had its first publication [15]. The concept is coincidentally similar to ours: coding history into statistical datasets. However, they suffered from a controversial matter regarding data treatment and statistical analysis $[16,17]$. From my experience, they probably can try Bayesian statistics, with simulations and the ability to deal with a small number of data [18].

Nonetheless, all these stories [11-15] pointed to the same conclusion: Ancient data are timeless. At the moment, we have enough power to dig deep into the historical materials and use statistical analysis to unearth the hidden stories. For a country that is proud of its history, it seems like a perfect fit for Vietnam. Moreover, due to the age of data, they can be accessed cheaply and even freely. These bonuses are valuable in the era of open data [19] and in the process of reducing the cost of science [20]. 


\section{References}

[1] Baker, M. (2016). Reproducibility crisis. Nature, 533(26), 353-366.

[2] Munafò, M. R., et al. (2017). A manifesto for reproducible science. Nature Human Behaviour, 1(1), 1-9.

[3] Fanelli, D. (2018). Opinion: Is science really facing a reproducibility crisis, and do we need it to?. Proceedings of the National Academy of Sciences, 115(11), 26282631.

[4] Haas, B. D. (2021). What my retraction taught me. Nature, 589, 331.

[5] Hoang, V. Q., \& Dung, T. T. (2009) The cultural dimensions of the Vietnamese private entrepreneurship. IUP Journal of Entrepreneurship Development, VI(3-4), 54-78.

[6] Vuong, Q. H., et al. (2018). An open database of productivity in Vietnam's social sciences and humanities for public use. Scientific Data, 5, 180188.

[7] Vuong, Q. H. (2014). Vietnam's Political Economy: A Discussion on the 1986-2016 Period. CEB Working Papers Series, N¹4-010, Université Libre de Bruxelles, Brussels, Belgium.

[8] Chính, P. M., \& Hoàng, V. Q. (2009). Kinh tế Việt Nam: Thăng trầm và đột phá. Nxb Chính trị Quốc gia, Hà Nội.

[9] Vuong, Q. H., Dam, V. N., van Houtte, D., \& Tran, T. D. (2011), The entrepreneurial facets as precursor to Vietnam's economic renovation in 1986. IUP Journal of Entrepreneurship Development, VIII(4), 6-47.

[10] Ebert, R. (2016). Reflections after 25 years at the movies. Roger Ebert. Retrieved from https://www.rogerebert.com/roger-ebert/reflections-after-25-years-at-the$\underline{\text { movies }}$

[11] Vuong, Q. H., et al. (2018). Cultural additivity: Behavioural insights from the interaction of Confucianism, Buddhism, and Taoism in folktales. Palgrave Communications, 4, 143.

[12] Vuong, Q. H., et al. (2020). On how religions could accidentally incite lies and violence: Folktales as a cultural transmitter. Palgrave Communications, 6, 82.

[13] Vuong, Q. H., et al. (2019). Cultural evolution in Vietnam's early 20th century: a Bayesian networks analysis of Hanoi Franco-Chinese house designs. Social Sciences \& Humanities Open, 1(1), 100001.

[14] Ngo, B. C., et al. (2020). The 80-year development of Vietnam mathematical research: Preliminary insights from the SciMath database on mathematicians, their works and their networks. arXiv Preprint; arXiv:2011.09328. 
[15] Whitehouse, $H_{\text {., }}$ et al. (2019). Complex societies precede moralizing gods throughout world history. Nature, 568, 226-229.

[16] Beheim, B., et al. (2019). Corrected analyses show that moralizing gods precede complex societies but serious data concerns remain. PsyArXiv preprints, doi:10.31234/osf.io/jwa2n

[17] Savage, P. (May 5, 2019). Additional robustness analyses confirm that complex societies precede moralizing gods throughout world history. Nature Ecology \& Evolution Community. Retrieved from: http://go.nature.com/2MdPKG0

[18] Vuong, Q. H., et al. (2020). Bayesian analysis for social data: A step-by-step protocol and interpretation. MethodsX, 7, 100924.

[19] Vuong, Q. H. (2017). Open data, open review and open dialogue in making social sciences plausible. Nature: Scientific Data Updates. Retrieved from: https://go.nature.com/2QdnUrW

[20] Vuong, Q. H. (2018). The (ir)rational consideration of the cost of science in transition economies. Nature Human Behaviour, 2(1), 5. 